\title{
COVID-19: A Global Pandemic
}

Dr. Ansh Agarwal ${ }^{1 *}$, Dr. Monika Gupta ${ }^{2}$, Mathur $\mathrm{P}^{3}$, Gupta $\mathrm{A}^{4}$

${ }^{1}$ Dr. Ansh Agarwal, Intern, Department of Pediatrics, Sawai Man Singh Medical College, Jaipur, Rajasthan, India

${ }^{2}$ Dr. Monika Gupta, Senior Resident, Department of Microbiology, Sawai Man Singh Medical College, Jaipur, Rajasthan, India

${ }^{3}$ Dr. Priyanshu Mathur, Associate Professor, Department of Pediatrics, Sawai Man Singh Medical College, Jaipur, Rajasthan, India

${ }^{4}$ Dr. Ashok Gupta, Senior Professor, Department of Pediatrics, Sawai Man Singh Medical College, Jaipur, Rajasthan, India

DOI: $10.36347 /$ sjams.2021.v09i03.035

| Received: 05.02.2021 | Accepted: 26.02.2021 | Published: 30.03.2021

*Corresponding author: Dr. Ansh Agarwal

Abstract

Review Article

COVID-19 is caused by novel $\beta$-coronavirus (SARSCoV2). It was first discovered in 2019, in Wuhan (seafood market), China. It was declared a global pandemic on $30^{\text {th }}$ Jan 2020 by the WHO. Person to person transmission via respiratory droplets is source of infection. The incubation period is 2 weeks from exposure. Middle aged and elders $>70$ years age or people with co-morbid conditions like Diabetes mellitus, lung diseases, obesity, immunecompromised state and kidney diseases predominantly affecting and leads to rise in mortality. Environmental contamination via contaminated surfaces in areas with high infective cases like quarantine centers or hospitals are also an important aspect of spreading the virus. So, routine cleaning with sodium dichloroisocyanourate disinfectant is needed. Protective antibodies against SARSCoV2 receptors binding domain of spike protein and nucleocapsid protein appears on day 14 following symptom onset. The antibody titers by Enzyme linked Immunosorbent assay (ELISA) correlates with neutralizing activity and protective nature of antibody. To understand the risk of reinfection, serological screening tool will be an important tool for population immunity or people already infected. SARS CoV 2 and SARS CoV share similar spike protein gene and RBD, i.e. capability of viral transmission in humans. Whole genome sequencing of SARS CoV 2 is similar to SARS like bat CoVs. Symptoms may appear 2-14 days after exposure to the virus. Most common and severe manifestation is pneumonia which presents with fever, cough, dyspnea and bilateral lung infiltrates on chest imaging. Specimen is collected from upper respiratory tract (nasopharynx and/or oropharynx) and lower respiratory tract (such as sputum, Broncho Alveolar Lavage (BAL). The diagnosis can be made via RT-PCR, Rapid antigen test, Rapid antibody test etc. but disease progression can be seen via radiological test like chest X-ray and CT. The mainstay of therapy of COVID-19 is supportive and preventive requiring quarantine and waiting self-recovery.

Keywords: COVID-19, SARS CoV 2, Pandemic, Environmental contamination, Quarantine, Sodium Dichloroisocyanourate, RT-PCR.

Copyright (C) 2021 The Author(s): This is an open-access article distributed under the terms of the Creative Commons Attribution 4.0 International License (CC BY-NC 4.0) which permits unrestricted use, distribution, and reproduction in any medium for non-commercial use provided the original author and source are credited.

\section{INTRODUCTION}

Coronaviruses are the most newly emerging zoonotic virus which is transmitted between animals and humans. [1] Previously, known effects of coronaviruses are common cold, severe acute respiratory syndrome (SARS) and middle-east respiratory syndrome (MERS). [2] Many more coronaviruses still present in environment which are not found in humans till now [3-5].

Coronavirus disease is caused by coronaviruses which first discovered from Wuhan, China in Dec 2019 [6]. This virus was not previously identified in humans. On $12^{\text {th }}$ January 2020, World Health Organization (WHO) renamed it as 2019-novel coronavirus (2019-nCoV) and subsequently, on $11^{\text {th }}$
February 2020, International committee on Taxonomy of Viruses of WHO coronavirus study group, named SARS CoV 2 and disease called COVID-19 [7-9].

In the end of year 2019, many cases which were identified as pneumonia Wuhan. Later, it was discovered that the pneumonia caused by a new strain of virus SARS-CoV2. Due to rapid increase in cases in a very short period of time, on $30^{\text {th }}$ January 2020, outbreak was declared by Public Health Emergency of International Concern (PHEIC) and global pandemic declared by the WHO [10]. At that time, epicenter of pandemic was Wuhan which later changed to Europe and USA [11, 12]. In the beginning of outbreak, studies in Wuhan's seafood market which sold alive animals for food purposes, showed initial association of 
infection to people working or visited the market. Later, the market was closed for disinfection purpose [13]. Now, as outbreak is progressing, person to person transmission became primary source. Due to animal spread of virus, it was necessary to find the infection in domestic animals transmitting to humans. Studies showed absence of any evidence of infectivity with pets. However, an experimental study showed viral multiplication in cats if intranasal inoculated. But Center for Disease Control (CDC) recommends that pets should be kept away from other animals or people outside the household.

\section{Mode of transmission and infectivity period of disease}

Dominant way of transmission is respiratory droplets released via cough, sneeze, talks etc. Infection occurs due to inhalation or touching the contaminated surfaces with droplets and then touches own mouth, nose and eye $[14,15]$. The aerosol spread is uncommon but a report revealed virus remains in aerosols for about three hours in experimental conditions [14]. The incubation period is 2 weeks after exposure, major occurs within 4-5 days as viral RNA peaks during this period. Virus is also likely to spread via non-respiratory methods like stool, blood and ocular secretions but no such study has substantial evidence to prove transmission [16, 17]. All ages and both sexes are equally affected. Middle aged and elders $>70$ years age or people with co-morbid conditions like Diabetes mellitus, chronic liver disease, lung disease, cardiovascular disease, obesity, immune-compromised state and kidney disease predominantly affecting and leads to rise in mortality [18-20].

Infectivity period is uncertain in COVID-19. Virus RNA from upper respiratory samples after symptoms onset is usually higher than later phases of disease $[15,21,22]$. So, the patient might be more infectious during earlier infection stage. If a viral RNA is detected in upper respiratory tract sample, that doesn't imply presence of infectious virus always. A study from China revealed infectiousness of virus starts 2-3 days before onset of symptoms and peaks in 7 hours and decline in 7 days, particularly after isolation [15]. However, patients without any symptoms can transmit the disease. In mild disease, most patients show negative tests in 10 days but in severe cases, patient shows longer duration of infectivity. So, if the patient's upper respiratory sample contain viral RNA, that doesn't correlate with infectivity of virus. According to a study, virus was not detected in respiratory sample when viral RNA level was $<10^{6}$ copies/ml [22].

Environmental contamination is also an important way of spreading the virus. Contaminated surfaces contain viruses in areas with high infective cases like quarantine centers or hospitals [14]. So, routine cleaning with sodium dichloroisocyanourate disinfectant is needed. Various disinfectants like ethanol at concentration between $62-71 \%$ inactivates virus in one minute [24]. However, viral persistence on surface depends on type of surface, ambient temperature, relative humidity and size of initial inoculum $[25,26]$.

\section{Immunity and reinfection}

Studies revealed presence of protective antibodies against receptors binding domain of spike protein and nucleocapsid protein appears on day 14 following symptoms onset. The antibody titers by Enzyme linked Immunosorbent assay (ELISA) correlates with neutralizing activity of antibodies that states protective nature of antibody [22]. The US-FDA authorized tests that qualitatively identifies antibody against SARS-CoV 2 in blood [27]. To understand the reinfection risk, serological screening can be an important investigation for population immunity or people already infected.

\section{Coronavirus structure and genome}

SARS-CoV 2 is a $\beta$-coronavirus which is enveloped non-segmented positive sense single stranded RNA virus. It belongs to subfamily Orthocoronaviridae and family Coronaviridae $[11,54]$. The genera are as alpha $(\alpha)$, beta $(\beta)$, gamma $(\gamma)$ and delta $(\delta)$. Alpha $(\alpha)$ and beta $(\beta)$ infect animals and gamma $(\gamma)$ and delta $(\delta)$ infect birds. There are six coronaviruses which infects humans in $\alpha \mathrm{CoV}$ is HCoV229E \& HCoVNL63 and $\beta$ $\mathrm{CoV}$ is $\mathrm{HCoV}-\mathrm{HKU} 1, \mathrm{HCoV}-\mathrm{OC} 43$, SARS-CoV and MERS CoV. Coronavirus structure is round or elliptical, often pleomorphic with diameter 60-140 nm. Two third of viral RNA is located in first open reading frame $(\mathrm{ORF} 1 \mathrm{a} / \mathrm{b})$ and encodes for 16 non-structural proteins (NSP). Remaining one third of viral RNA encodes essential structural proteins like spike (S) glycoprotein, small envelope (E) protein, matrix (M) protein, nucleocapsid $(\mathrm{N})$ protein and accessary proteins which interfere with host immune system [29, 30].

SARS CoV 2 and SARS CoV share similar spike protein gene and RBD, i.e. capability of viral transmission in humans [31]. Whole genome sequencing of SARS CoV 2 is similar to SARS like bat CoVs. Chan et al. proven that genome of new $\mathrm{CoV}$ isolated from cluster patients with atypical pneumonia showed $89 \%$ nucleotides similar to bats SARS CoV like CoV2XC21 and $82 \%$ similar with human SARS CoV [4]. That's why new virus called SARS CoV 2 and bats are suspected as natural host of virus origin. Another study revealed mutation in non-structural proteins of COVID-19 which is playing a role in its infectious capability and differentiation mechanism. So, there is need of regular monitoring of current $\mathrm{CoV}$ for their virulence and epidemic spread.

\section{Clinical manifestations}

Like any other viral infection, COVID-19 also presents with similar complains. Symptoms may appear 2-14 days after exposure to the virus. Most common and severe manifestation is pneumonia which presents with fever, cough, dyspnea and bilateral lung infiltrates 
Ansh Agarwal et al; Sch J App Med Sci, Mar, 2021; 9(3): 481-486

on chest imaging. Worldwide, there are several other symptoms presented by COVID-19 positive patients like fatigue, dry cough, anorexia, myalgia, sputum production, diarrhea, nausea and vomiting etc. [19, 39].

The CDC prepared a check list for symptoms presented by COVID-19 affected patients are fever or chills with/without rigor, cough, dyspnea, fatigue, body ache, headache, new taste loss or smell, sore throat, congestion, runny nose, nausea, vomiting, diarrhea. The warning signs which may require emergency care or hospitalization are trouble breathing, pressure in the chest or pain, inability to wake or stay awake, new confusion $[40,41]$.

\section{DIAGNOSTIC METHODS}

\section{Collection, handling and storage}

Sample collection and storage is challenging for diagnosis of COVID-19. The WHO recommends specimen collection from upper respiratory tract (nasopharynx and/or oropharynx) and lower respiratory tract (such as sputum, Broncho Alveolar Lavage (BAL) or endotracheal aspirate). BAL collected only in patients on mechanical ventilation. Lower respiratory tract samples are stored at $4^{\circ} \mathrm{C}$ [42].

\section{RT-PCR}

Reverse transcriptase polymerase chain reaction (RT-PCR) is used for amplification of genetic material collected from specimen. It involves synthesis of double stranded DNA from RNA of virus. The whole procedure involves three steps; lysis, extraction and PCR. Lysis buffer is used to get a lysate from the specimens and then the nucleic acids are to be recovered using automated extraction system, and also by manual extraction following manufacturer's instruction. RT-PCR should be performed on the extraction eluter of specimens. Pooling can also be employed at where samples are collected in big amount. Two stage approaches is followed and then any positive pools are tested later to determine which individual is positive. This approach can save reagents and also reduces the turnaround time. The CDC recommends identifying the presence of nucleic acid targets specific to SARS CoV 2. The test is based on the initial genetic sequence released by Shanghai public health clinical center and school of public health, Fudan University, Shanghai, China [43].

The US CDC have developed a kit containing PCR primer probe sets for two regions of viral nucleocapsid gene (N1 and N2) and for humans RNase $\mathrm{P}$ gene to ensure successful RNA extraction. The WHO primer probe sets target the SARS CoV 2 RNA dependent RNA polymerase and envelope (E) genes [44]. These tests use cycle threshold (CT) of $<40$ to be positive. Both above tests are highly sensitive and specific with minimal cross reactivity with other coronavirus strains.
If a patient showed a positive test result, then at least two upper respiratory tract samples collected in 24 hour interval to be negative to document SARS CoV 2 clearance before release from observation [45]. Many new tests have been introduced for COVID-19 but their diagnostic accuracy is questionable because of lack of incomplete understanding of virus, different methods of collecting and preparing the samples and absence of standard test.

\section{Viral culture}

Viral culture using Vero-CCL-81 cells is possible but not commonly used because of low sensitivity and long turnaround time for virus detection [46].

\section{Rapid antigen detection test}

RDT detects presence of SARS CoV 2 antigen from samples which bind to specific antibodies fixed to a paper strip. Samples are taken from nasopharyngeal / nasal swab which is directly placed into extraction buffer or reagent. The test shows visually detectable signals usually in 30 minutes. The test limitation is only when virus is actively replicating, test result varies with illness onset, concentration and quality of specimen, reagents in test kit $[47,48]$. False positive result due to antibodies on stripe recognizes antigens of virus other than SARS CoV 2 like SARS CoV. Monoclonal antibody against nucleocapsid protein of SARS CoV 2 has been developed [49]. The advantages of the test are inexpensive, can be used bedside and for surveillance of testing. Its results are more sensitive and specific when done early in infection, when viral load is highest.

\section{Rapid antibody diagnostic test}

The basis of test is the detection of $\operatorname{IgM}$ and IgG antibodies. [50-53] The ELISA or rapid card test can be used to detect antibodies. IgG antibodies appear after two weeks of symptom onset or with recovery, i.e. its use is limited in management and transmission prevention of SARS CoV 2. The negative test doesn't exclude recent infection. However, it can be used with RT-PCR for antibody response. This test may not be used to diagnose an active infection. In general, a positive antibody test is presumed to mean a person has been infected with SARS CoV 2 but doesn't clarify presence of ongoing infection. It is hard to define immunity from reinfection if they have antibody against viral components.

\section{Radiological tests}

Plain chest $\mathrm{X}$-ray is an early and easy supportive test for management. Chest X-ray shows bilateral pulmonary infiltrates.

Computed tomography (CT) of chest is more sensitive than plain chest $\mathrm{X}$-ray. Most CT finding shows predominant peripheral, bilateral, lower lobes involvement with ground glass opacities or mixed ground glass opacity and consolidation, vascular involvement, traction bronchiectasis. The limitation is 
Ansh Agarwal et al; Sch J App Med Sci, Mar, 2021; 9(3): 481-486

presence of any co-infection or alternative diagnosis [54].

\section{Laboratory tests}

COVID-19 infected patient shows decreased albumin, elevated C-reactive protein, elevated lactate dehydrogenase level and lymphopenia [55]. In severe cases with multi organ involvement, patients show elevated erythrocyte sedimentation rates, elevated aspartate aminotransferase, elevated alanine aminotransferase, elevated creatinine kinase level, leukopenia, leukocytosis increased bilirubin and creatinine levels $[18,19]$.

\section{Management [56] \\ Management of mild cases}

Patients complain of fever or upper respiratory infections are isolated. Patients with these symptoms can present to primary care centers, outpatient department (OPD) or community outreach activities. These patients can be treated at Covid Centres or home isolation. Patient's detailed clinical history with comorbidities taken and counsel about warning signs. If a patient have co-morbidities then closely monitored and in emergency, immediately shifted to Covid care center or Covid hospital.

In mild cases, patients are followed up daily for temperature, vitals and oxygen saturation $\left(\mathrm{SpO}_{2}\right)$ monitoring. They can be treated symptomatically with antipyretics, adequate hydration and nutrition.

\section{Management of moderate cases}

Patients complain of fever, cough, and dyspnea (likely has pneumonia) or have $>24$ breaths per minute respiratory rate and oxygen saturation $\left(\mathrm{SpO}_{2}\right)<94 \%$; is been isolated in Covid care center or Covid hospital. The detailed clinical history with co-morbidities, vital signs monitoring, $\mathrm{SpO}_{2}$, chest $\mathrm{x}$-ray and other indicated investigations are done. In moderate cases, treatment done with oxygen support (target $\mathrm{SpO}_{2}$ is $92-96 \%$ and $88-92 \%$ in COPD patients). If HFNC or simple nasal cannula used, then N95 mask should be applied with it. Awake proning used as a rescue therapy. Patients daily monitored with 12 lead ECG, complete blood count with differentials, Absolute lymphocyte count, renal function tests and liver function tests with follow up Creactive protein, D-dimer and ferritin every 48 hours. Tab Hydroxychloroquine 400mg BD first day followed by $200 \mathrm{mg}$ BD for 4 days (after ECG Assessment). Consider IV methylprednisolone 0.5 to $1 \mathrm{mg} / \mathrm{kg} 3$ days (within 2 days of admission or if oxygen requirement is increasing and if inflammatory markers increased). Anticoagulants are given prophylactically unfractionated heparin (UFH) or low molecular weight heparin (LMWH) (Enoxaparin $40 \mathrm{mg}$ per day SC). Close monitoring of patients is required for disease progression.

\section{Management of severe cases}

Patients complain of severe respiratory distress requiring mechanical ventilation or $>30$ breaths per minute and $\mathrm{SpO}_{2}<90 \%$; are isolated and given supplemental oxygen therapy immediately. Initially oxygen therapy at $5 \mathrm{~L} / \mathrm{min}$ and titrate the flow at a rate to achieve $\mathrm{SpO}_{2} \geq 90 \%$. Children with warning signs receive oxygen therapy during resuscitation to reach $\mathrm{SpO}_{2} \geq 94 \%$.

Currently, there are several therapies under trial given to specific patients only. Remdesivir is an investigational nucleotide analog with broad spectrum antiviral activity. The drug dose is $200 \mathrm{mg}$ IV followed by $100 \mathrm{mg}$ IV daily 5 days. The drug is contraindicated in patients with AST/ALT > 5 times, renal impairment (i.e. GFR $<30 \mathrm{ml} / \mathrm{min} / \mathrm{m} 2$ or hemodialysis), pregnant, lactating females and children $<12$ years of age.

Convalescent plasma can be used in patients with moderate disease who are not showing signs of improvement. Precautions include ABO compatibility, cross matching of the donor plasma and neutralizing titer of donor plasma. Post transfusion monitoring of patients done for transfusion related adverse reactions and avoid if $\operatorname{Ig}$ A deficiency or immunoglobulin allergy. The dose can be $4-13 \mathrm{ml} / \mathrm{kg}$ or $200 \mathrm{ml}$ single dose over more than 2 hours.

Tocilizumab can be used with moderate disease with progressively increasing oxygen requirements and in mechanically ventilated patients not showing signs of improvement. The prerequisites include raised inflammatory markers (e.g. CRP, Ferritin, IL-6), secondary infections and neutropenia, active infections and Tuberculosis should be ruled out. The dose can be $8 \mathrm{mg} / \mathrm{kg}$ (maximum $800 \mathrm{mg}$ at one time) given slowly in $100 \mathrm{ml}$ Normal Saline over 1 hour (can be repeated once after 12 to 24 hours if needed).

\section{Summary AND CONCLUSION}

COVID-19 is caused by $\beta$-coronavirus (SARS CoV 2), discovered in Wuhan (seafood market), China in 2019 and declared pandemic on $30^{\text {th }}$ Jan 2020 by the WHO. The transmission via respiratory droplets like sneeze, coughing etc. is primary source. The incubation period is 2 weeks after exposure. Middle aged and elders >70 years age or people with co-morbidity predominantly affected and leads to rise in mortality. Environmental contamination via contaminated surfaces in areas with high infective cases like quarantine centers or hospitals are also an important cause of virus transmission. So, routine cleaning with sodium dichloroisocyanourate disinfectant is needed. Protective antibodies against SARS $\mathrm{CoV} 2$ receptors binding domain appear on day 14 after symptom onset. The antibody titers can correlate with neutralizing and protective activity of antibody. To estimate the reinfection risk, serological screening tool can be used as an important investigation for immunity or people already infected. SARS CoV 2 and SARS CoV share 
Ansh Agarwal et al; Sch J App Med Sci, Mar, 2021; 9(3): 481-486

similar spike protein gene and RBD, i.e. capability of viral transmission in humans. Whole genome sequencing is similar to SARS like bat CoVs. Symptoms may appear 2-14 days after exposure. Most common and severe manifestation is pneumonia which presents with fever, cough, dyspnea and bilateral lung infiltrates on chest imaging. Specimen is collected from upper respiratory tract (nasopharynx and/or oropharynx) and lower respiratory tract (such as sputum, Broncho Alveolar Lavage (BAL) or endotracheal aspirate). The diagnosis can be made via RT-PCR, Rapid antigen test, Rapid antibody test etc. but disease progression can be seen via radiological tests. The mainstay of management is quarantine and symptomatic treatment.

\section{REFERENCES}

1. Coleman CM, Frieman MB. Coronaviruses: Important emerging human pathogens. J Virol. 2014;88:5209-12

2. Yin Y, Wunderink RG. MERS, SARS and other coronaviruses as causes of pneumonia. Respirology. 2018; 23:130-7.

3. Jones KE, Patel NG, Levy MA, Storeygard A, Balk D, Gittleman JL. P. Daszak (2008), «. Global trends in emerging infectious diseases». Nature. 3;451(7181):990-3.

4. Li W, Shi Z, Yu M. Bats are natural reservoirs of SARS-like coronaviruses. Science 2005;310:6

5. Zaki AM, van Boheemen S, Bestebroer TM. Isolation of a novel coronavirus from a man with pneumArabia. N Engl J Med. 2012; 367:1814-20.

6. Lu R, Zhao X, Li J, Niu P, et al. Genomic characterisation and epidemiology of 2019 novel coronavirus: Implication and receptor binding. Lancet. 2020; 395:565-74.

7. WHO. Coronavirus disease (COVID-2019) situation reports. 2020. Available from: https://www.who.int/emergencies/diseases/nov201 9/situationreports. [Last accessed on 2020 Mar 05].

8. World Health Organization. Director-General's remarks at the media briefing on 2019-nCoV on 11 February 2020. Available from https://www.who.int/dg/speeches/detail/whodirector-general-s-remarks-at-the-media-briefing-o n-2019-ncov-on-11-february-202 2020 Feb 12].

9. Centers for Disease Control and Prevention. First travel-related case of 2019 novel coronavirus detected in United States, January from: https://www.cdc.gov/media/releases /2020/p0121novel-coronavirus-travel-case.html. [Last accessed on 2020 Jan 21].

10. Zhu N, Zhang D, Wang W. A novel coronavirus from patients with pneumonia in China, 2019. N Engl 2020; 382:727-33.

11. WHO. Coronavirus disease (COVID-2019) situation reports 2020. Available from: https://www.who.int/emergencies/diseases/no v2019/situationreports. [Last accessed on 2020 Mar 21].
12. European Centre for Disease Prevention and Control. Novel coronavirus in China. Available from: https://www.ecdc.europa.eu/enchina. [Last accessed on Jan 23].

13. World Health Organization. Novel coronavirus situation report -2. January 22, 2020. Available from: https://www.who.int/docs/deviruse/situationreports/20200122-sitr ep-2-2019-ncov.pdf. [Last accessed on 2020 Jan 23].

14. Van Doremalen N, Bushmaker T, Morris DH. Aerosol and surface stability of SACompared with SARS-CoV-1. N Engl J Med. 2020; 382:1564-7.

15. Zou L, Ruan F, Huang M. SARS-CoV-2 viral load in upper respiratory specimens of infected. 2020; 382:1177-9.

16. Chen W, Lan Y, Yuan X. Detec[table 2019]-nCoV viral RNA in blood is a strong indicator for the fourth Emerg Microbes Infect 2020;9:469-73.

17. Wang W, Xu Y, Gao R. Detection of SARS-CoV-2 in different types of clinical specimens. JAMA. 20202020.3786.

18. Huang C, Wang Y, Li X. Clinical features of patients infected with 2019 novel coronavirus in Wuhan, C 2020;395:497-506.

19. Chen N, Zhou M, Dong X. Epidemiological and clinical characteristics of 99 cases of 2019 novel corona in Wuhan, China: A descriptive study. Lancet. 2020;395:507-13.

20. Onder G, Rezza G, Brusaferro S. Case-fatality rate and characteristics of patients dying in relation to COVID-19 in Italy [published print, 2020 Mar 23]. JAMA 2020. doi: 10.1001/jama. 2020.4683

21. Yu F, Yan L, Wang N. Quantitative detection and viral load analysis of SARS-CoV-2 in infected patient Dis 2020. doi: 10.1093/cid/ciaa345.

22. AABB. AABB's Coronavirus Resources. Available from:

http://www.aabb.org/advocacy/regulatorygovernme nt/Pages/AABB-Corrces.aspx. [Last accessed on 2020 Apr 21].

23. Hu Z, Song C, Xu C. Clinical characteristics of 24 asymptomatic infections with COVID-19 screened in Nanjing, China. Sci China Life Sci. 2020; 63:706-11.

24. Park SY, Kim YM, Yi S, et al. Coronavirus disease outbreak in call center, South Korea [published online Apr 23]. Emerg Infect Dis. 2020;26.

25. Ghinai I, Woods S, Ritger KA. Community transmission of SARS-CoV-2 at two family in Chicago, Illinois, February-March 2020. MMWR Morb Mortal Wkly Rep. 2020; 69:446-50.

26. Kampf G, Todt D, Pfaender S. Persistence of coronaviruses on inanimate surfaces and their inactivation with biocide Infect. 2020;104:246-51.

27. Kimball A, Hatfield KM, Arons M. Asymptomatic and presymptomatic SARS-CoV-2 infection longterm care skilled nursing facility-King County, Washington, March. 2020. MMWR Morb Mortal Wkly Rep. 2020; 69:377-81. 
Ansh Agarwal et al; Sch J App Med Sci, Mar, 2021; 9(3): 481-486

28. de Wit E, van Doremalen N, Falzarano D. SARS and MERS: Recent insights into emerging coronaviruses. Nat Rev M. 2016; 14:523-34.

29. Song $\mathrm{Z}, \mathrm{Xu} \mathrm{Y}$, Bao L. From SARS to MERS, thrusting coronaviruses into the spotlight. Viruses 2019;1 10.3390/v11010059.

30. Wu F, Zhao S, Yu B. A new coronavirus associated with human respiratory disease in China. 2020; 579:265-9.

31. Wu A, Peng Y, Huang B. Genome composition and divergence of the novel coronavirus (2019-nCoV China. Cell Host Microbe; 2020; 27:325-8.

32. Jia HP, Look DC, Shi L. ACE2 receptor expression and severe acute respiratory syndrome corona depend on differentiation of human airway epithelia. J Virol 2005; 79:14614-21.

33. Wan Y, Shang J, Graham R. Receptor recognition by novel coronavirus from Wuhan: An analysis based on decade studies of SARS. J Virol 2020; 94:e00127-20.

34. Zhang N, Jiang S, Du L. Current advancements and potential strategies in the development of MERSCoV vaccines. Expert Rev V; 2014;13:761-74.

35. Xia S, Zhu Y, Liu M, et al. Fusion mechanism of 2019- nCoV and fusion inhibitors targeting HR1 domain in Mol Immunol; 2020.

36. Yu F, Du L, Ojcius DM. Measures for diagnosing and treating infections by a novel coronavirus responsible for originating in Wuhan, China. Microbes Infect; 2020.

37. Sawicki SG, Sawicki DL. Coronavirus transcription: A perspective. Curr Top Microbiol Immunol. 2005; 287:31-55.

38. Chu KH, Tsang WK, Tang CS. Acute renal impairment in coronavirus-associated severe acute respiratory and Kidney Int. 2005;67:698-705

39. Wang D, Hu B, Hu C. Clinical characteristics of 138 hospitalized patients with 2019 novel coronavirus pneumonia in Wuhan, China. JAMA 2020; 323:1061-9.

40. Goyal P, Choi JJ, Pinheiro LC. Clinical characteristics of Covid-19 in New York City. N Engl J 10.1056/NEJMc2010419.

41. CDC-USA. Available https://www.cdc.gov/coronavirus/2019-ncov/sy mptoms-testing/sympto ms.html. [Last accessed on 20

42. Wölfel R, Corman VM, Guggemos W. Virological assessment of hospitalized patients 2020 Apr 1]. Nature 2020.

43. Cascella M, Rajnik M, Cuomo A. Features, Evaluation and Treatment Coronavirus (COVID19) [Updated In: StatPearls [Internet]. Treasure Island (FL): StatPearls Publishing; 2020 Jan.
44. Corman VM, Landt O, Kaiser M. Detection of 2019 novel coronavirus (2019-nCoV) by Euro Surveill. 2020;25.

45. Centers for Disease Control and Prevention. Discontinuation of Transmission-Based Precautions and Disposition of Patients with Healthcare Settings (Interim Guidance). Available from: $\quad$ www.cdc.gov/coronavirus/2019. ncov/hcp/disposition-hospitalized-patient accessed on 2020 Apr 04].

46. Charlton CL, Babady E, Ginocchio CC. Practical guidance for clinical microbiology laboratory acute respiratory tract infections. Clin Microbiol Rev. 2019; 32:e00042-118.

47. Advice on the use of point-of-care immunodiagnostic tests for COVID-19. Available from:

https://www.who.int/newsroom/commentaries/detai 1/advice-on-the-use-of-point-of-care-

immunodiagnostic-tests-for-covid-19.

[Last accessed 2020 Apr 8].

48. Cheng MP, Papenburg J, Desjardins M. Diagnostic testing for severe acute respiratory syndrome coronavirus-2: A narrative review. Ann Intern Med 2020. doi: 10.7326/M20-1301.

49. Sheridan C. Fast, portable tests come online to curb coronavirus pandemic. Nat Biotechnol 2020.

50. Liu Y, Liu Y, Diao B. Diagnostic indexes of a rapid IgG/IgM combined antibody2020 Mar 26

51. Zhang P, Gao Q, Wang T. Evaluation of recombinant nucleocapsid and spice protein serological diagnosis coronavirus disease 2019 (COVID-19). medxriv [Internet]. 2020; Available from:

https://www.medrxiv.org/content/10.1101/2020.

52. Pan Y, Li X, Yang G. Serological immunochromatographic approach in diagnosis with SARS-CoV-2 patients. medxriv [Internet]. 2020. Available from: https://doi.org/10.1101/2020.03.13.20035428.

53. Li Z, Yi Y, Luo X, et al. Development and clinical application of a rapid IgM-IgG combined antibody test for infection diagnosis. J Med Virol 2020.

54. Wu X, Cai Y, Huang X. Co-infection with SARSCoV-2 and influenza $A$ virus in patient with pneumonia Infect Dis. 2020;26.

55. Rodriguez-Morales AJ, Cardona-Ospina JA, Gutiérrez-Ocampo E. Network of Coronavirus Disease 2019-COVID-19 Research (LANCOVID19). Clinical, laboratory and imaging features of COVID-19 review and meta-analysis. Travel Med Infect Dis. 2020:101623.

56. Clinical management protocol: COVID-19 Government of India Ministry of Health and Family Welfare Directorate General of Health Services (EMR Division) Version 3 13.06.20. 